\title{
Morphological analysis and photosynthetic performance of improved papaya genotypes
}

\section{Alena Torres Netto ${ }^{1 *}$, Eliemar Campostrini', Letícia C. Azevedo², Marcelo A. de Souza ${ }^{3}$, José C. Ramalho ${ }^{4}$ and Manuela M. Chaves ${ }^{5}$}

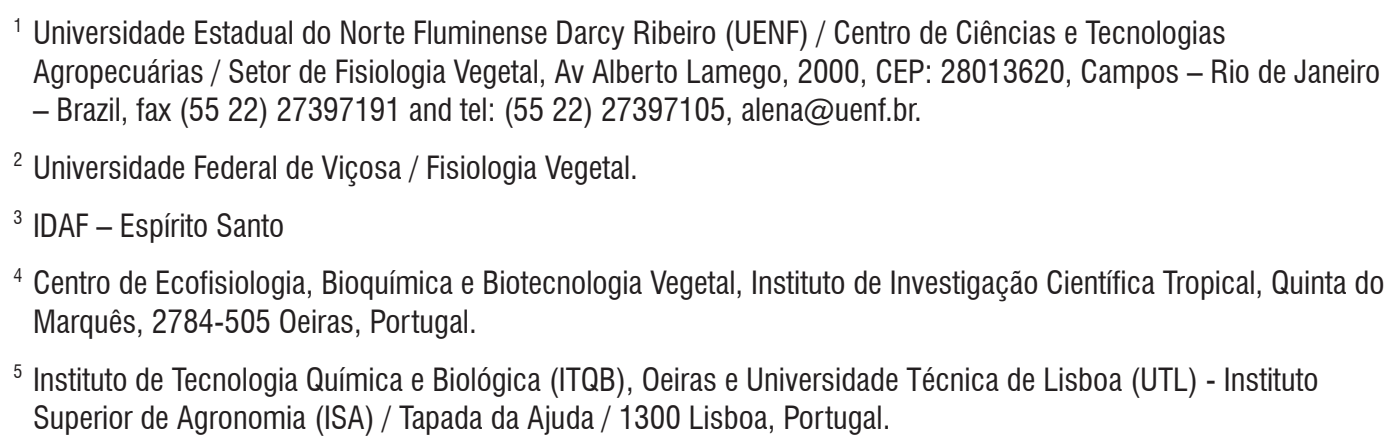

Received: 19 June 2009; Accepted: 21 October 2009.

\begin{abstract}
Brazil is the largest world producer of papaya and the third largest exporter despite of only 1.5 to $2.0 \%$ of its production is exported. Such an underexplored exportation potential highlight the necessity for physiological studies on new cultivars and hybrids to verify their agronomic and commercial viability. Two Brazilian states, Bahia and Espirito Santo, are responsible for $80 \%$ of national production. Papaya can also be an agricultural alternative to north / northeast of Rio de Janeiro, because the region is close to consumer centers and have similar environmental conditions of the most productive regions. Nevertheless, it is worth to develop cultivars that can express the highest yield potential in this region. The aim of this work was to characterize physiologically two hybrids developed for the north/northeast of Rio de Janeiro (UENF/Caliman 01 and JS12) in comparison with three top commercial genotypes (Golden, Sunrise Solo 7212 and Tainung) of Carica papaya L.. The cv. Golden presented the lowest shoot and root growth, the lowest height, shrunk diameter, specific leaf weight, less efficiency in electrons transport per sample area and show the lowest ability to synthesized total chlorophylls in comparison with the others genotypes. At noon, this genotype showed higher stomatal conductance, related to the leaf-air vapor pressure deficit, which lead to higher transpiration rate and intrinsic water use efficiency. No differences were detected in the photosynthetic rates among the five genotypes suggesting that the UENF`s hybrids are endowed with similar photosynthetic capacity and morphological characteristics to the top commercial genotypes. The relevance of this characterization to drive future successful genetic improvement programs will be discussed.
\end{abstract}

Key words: Carica papaya L., fluorescence, gas exchange, genotypes, growth analyses

\section{INTRODUCTION}

The carbon assimilates necessary for yield productions are ultimately produced via photosynthesis. Thus, any factor that substantially alters the net rate of photosynthesis $(A)$ has a potential impact on growth (Pettigrew, 2004). Total biomass accumulation is a function of the rate of biomass production (associated with leaf area production, leaf area retention and net photosynthetic rate) and growth duration (Peng et al., 1991).

The variability of genotype productivity can be associated with the morphological characteristics of the plant (architecture), 
growing patterns (growth rates and assimilate partitioning), photosynthetic efficiency and reproductive activity. Although at least $90 \%$ of the dry weight of higher plants is derived from $\mathrm{CO}_{2}$ assimilated by photosynthesis (Zelicht, 1982), genetic differences in crop productivity are strongly determined for the assimilated partitioning (Nelson, 1988), determining the agricultural income (Lawlor, 1995). Accordingly, improved plant photosynthesis coupled with optimal dry weight partitioning could lead to additional yield improvement (Pettigrew and Gerick, 2007).

The existence of inter and intra genetic variability in photosynthetic rate was discussed for a wide number of crop species, namely soybean (Wiebold et al., 1981), corn (Heichel and Musgrave, 1969), pea (Mahon and Hobbs, 1981), strawberry (Hancock et al., 1989), chickpea (Anilkumar et al., 1993), wheat (Watanabe et al., 1997), bean (Gonzáles et al., 1995) and cotton (Pettigrew and Turley, 1998). However, whether this variability can be used to improve crop production is not conclusive (Joshi, 1997). Improvement in one step may prove ineffective if another component remains limiting for the overall process (Pettigrew and Turley, 1998).

Before simultaneous breeding for increased yield and photosynthesis becomes routinely successful, identification of the variation in the components of the photosynthetic process must first be identified (Pettigrew and Turley, 1998). The yield genotypic differences found in cotton leaves were attributed to differences in leaf thickness or density (both evaluated by specific leaf weight, SLW), as well as to chlorophyll and proteins contents, being the high SLW correlated positively with the photosynthetic rate (Pettigrew and Turley, 1998). In fact, Dornhoff and Shibles (1970) earlier suggested that SLW can be used as an index to select higher photosynthetic rates in soybean genotypes, considering that this physiological parameter was well correlated with that morphological characteristic.

In relation the chlorophyll fluorescence, few studies have investigated genetic variation traits (Koehn et al., 2003). Pettigrew and Turley (1998) showed that some genetic variation exists in $\mathrm{CO}_{2}$ exchange rates and in the ratio of variable fluorescence to maximum chlorophyll fluorescence $\left(F_{\mathrm{v}} / F_{\mathrm{m}}\right)$ in Gossypium hirsutum L. genotypes that were bred for increased crop yield. Open pollinated families representing tall and short height classes in Pinus ponderosa Dougl. ex P. \& C. Laws differed in $F_{\mathrm{v}} / F_{\mathrm{m}}$ during spring and fall seasons, but no variation was detected among height classes in populations of Pseudotsuga menziesii var. glauca (Beissn.) Franco and Pinus monticola Dougl. ex D. Don (Marshall et al., 2001).
Environmental limitations often avoid genotypes from attaining their yield potential (Chaves et al., 2003). For example, a decrease in the photosynthetic rate during the afternoon, as compared to the morning values within the same light intensity. Several factors might contribute to this response, working alone or in tandem, the high temperature (Perry et al., 1983), a stomatal closure due to a rise of the vapor pressure deficit (VPD) (Pettigrew et al., 1990) or the existence of a feedback inhibition due to increased sugar levels in the leaves (Peet and Kramer, 1980). The genotypes that keep their photosynthesis in this period can produce more assimilates for plant growth and development. Therefore it is necessary to identify the genetic components that contribute for such limitation of the photosynthetic rates.

In cassava, significant differences in stomatal sensitivity to humidity were observed among cultivars (El-Sharkawy 2004). Furthermore, total biomass and storage root yield were larger in high humidity environments and these characteristics were positively correlated with leaf photosynthetic rates (Cock et al. 1985, El-Sharkawy et al. 1986). These findings illustrate that stomatal sensitivity to changes in air humidity is translated into crop canopy, and hence to productivity, and have important practical implications for cassava breeding for different ecosystems and edapho-climatic zones (El-Sharkawy 2006).

In Brazil, the Darcy Ribeiro State University of North Fluminense is involved in a wide program for genetic breeding of papaya (Carica papaya L.), aiming at the development of improved genotypes for the national and international market. However, little information is available about the interaction of environmental factors (climate and soil) and physiological processes (namely, photosynthesis) of these new genotypes (Marler et al., 1994). Such knowledge can decisively contribute to an efficient agricultural zoning, to build up correct management strategies aiming of higher productivity and to genetic breeding programs for papaya (Schaffer and Andersen, 1994, Reis et al, 2006, Singels et al., 2005, Campostrini and Glenn, 2007). In order to support genetic breeding programs of papaya, this work studied some photosynthetic and biometric components in five papaya genotypes (Carica papaya L.).

\section{MATERIAL AND METHODS}

Plant material and growth conditions: Plants of five Carica papaya L. genotypes (Sunrise Solo 72/12, Formosa, Golden, Tainung and hybrid UENF-Caliman) were grown in 
white pots with $6 \mathrm{~L}$ filled with soil: sand: manure (1:2:1). The experiment was done from September to December of 2003, in a greenhouse with ca. $30 \%$ of the natural photosynthetic photon flux density (PPFD), in the Darcy Ribeiro State University of North Fluminense, in Campos dos Goytacazes, Brazil $\left(41^{\circ} 15^{\prime} 0,21^{\circ} 27^{\prime} \mathrm{S}\right)$.
During the experiment relative humidity and temperature were measured by a thermohigrometer (Spectrum Technologies, USA), and PPFD by a Quantum Data Logger (Spectrum Technologies, USA). All sensors were coupled to a data collector and the information was taken every hour (Figure 1).
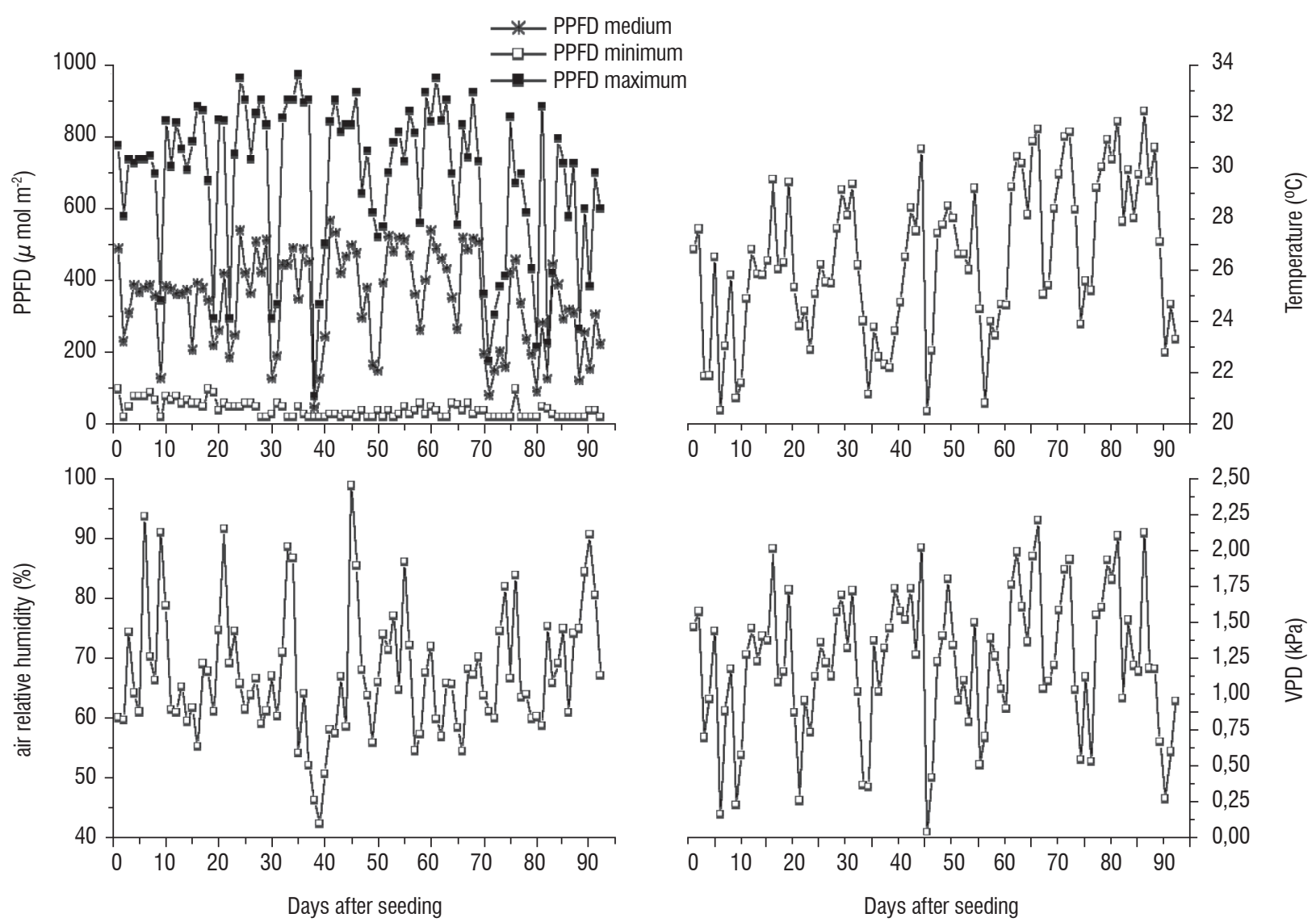

Figure 1. Photosynthetic photon flux density (PPFD), relative humidity, temperature and air vapor pressure deficit $\left(\mathrm{VPD}_{\text {air }}\right)$ from the growing location of the 5 genotypes of Carica papaya L.

Measurements: Fifteen days after germination the biometric measurements started and were carried out weekly, including the length of central vein (LCV) and plant height $(H)$, measured with a ruler, the stem diameter (D), using a caliper (Eletromir Digital Caliper) and the leaf number (NF). Leaf area per plant $\left(L A, m^{-2}\right)$ was obtained at the end of the experiment (92 days after seedling -DAS), using a LI-3100 area meter (LI-COR, Lincoln, NE, USA), the specific leaf weight
(SLW, $\mathrm{g} \mathrm{m}^{-2}$ ) was determined in each genotype at the same date by the rate of leaf disc dry weight and leaf disc area ratio (10 discs/genotype). Each disc had $10 \mathrm{~cm}^{2}$ and was sampled from the $4^{\text {th }}$ or $5^{\text {th }}$ leaf from the apex.

To determine the shoot and root dry weight (SDW and RDW, respectively) at the end of the experiment (92 DAS), the plant organs (leaves, stem and roots) were oven-dried at $80^{\circ} \mathrm{C}$ for $48 \mathrm{~h}$. Using the dry weight values several parameters 
were estimated: shoot: root ratio (SDW/RDW, $\mathrm{g} \mathrm{g}^{-1}$ ), leaf weight ratio (LWR, g leaf dry weight $\mathrm{g}^{-1}$ total plant dry weight), stem weight ratio (SWR, g stem dry weight $\mathrm{g}^{-1}$ total plant dry weight) and leaf area ratio (LAR, $\mathrm{m}^{2}$ leaf area $\mathrm{g}^{-1}$ total plant dry weight) (Cruz et al., 2004).

Net photosynthetic rates (A) and stomatal conductance $\left(g_{s}\right)$, as well as the leaf-to-air vapor pressure deficit (VPD leat-air $_{\text {in }}$ ) were measured between 35 - 49 days after seedling (DAS), at 800 and at $1200 \mathrm{~h}$, in the $4^{\text {th }}$ or the $5^{\text {th }}$ leaf from the apex, using a portable photosynthesis system model, LI-6200 (LI-COR). The daily carbon gain $\left(A_{\text {daily }}\right)$ was estimated by interposing the area below the daily net photosynthesis curve obtained by the measurements along the day (800,1200, 1400 and $1600 \mathrm{~h})$.

The chlorophyll content was estimated using the portable chlorophyll meter (PCM) (SPAD-502, Minolta, Japan) in the same leaves.

The intrinsic water use efficiency (IWUE, $\mu \mathrm{mol} \mathrm{CO}_{2}$ / $\mathrm{mmol} \mathrm{H}_{2} \mathrm{O}$ ) was determined at the end of the experiment, by dividing the net photosynthetic rate (A) by the stomatal conductance $\left(g_{s}\right)$.

Thechlorophyllafluorescence parameters weredetermined concomitantly to the gas exchange measurements, using a nonmodulated fluorimeter PEA (Plant Efficiency Analyzer-Hansatech Ltda., King's Lynn, UK). The leaves were pre-darkened for 30 min so that all reaction centers were "open" (all primary acceptors oxidized) and heat dissipation was minimal. After dark adaptation the chlorophyll fluorescence variables $F_{0}$ (initial fluorescence), $F_{m}$ (maximum fluorescence) and $F_{v} / F_{m}$ (maximum quantum yield) were determined. According to Strasser and Strasser (1995), using the PEA fluorimeter, it is possible to obtain five fluorescence levels $\left[F_{1}(t=50 \mu \mathrm{s}), F_{2}(t=100 \mu \mathrm{s}), F_{3}(t=300 \mu \mathrm{s})\right.$, $\left.F_{4}(t=2 m s), F_{5}(t=30 m s)\right]$. From those fluorescence data the JIP-test was performed using the Biolyser program (Strasser, R.J. - University of Geneva, Laboratory of Bioenergetics, Switzerland) to obtain some information about the behavior (structure, conformation and activity) of the photosynthetic apparatus. The calculated parameters were: $A B S / \mathrm{CS}_{0}$ (the total number of photons absorbed by the antenna molecules of active and inactive PS II reaction centers over the sample crosssection), $\mathrm{ET}_{0} / \mathrm{CS}_{0}$ (electron transport in a PS II cross-section), $\mathrm{RC} / \mathrm{CS}_{0}$ (concentration of active reaction centres), $\mathrm{TR}_{0} / \mathrm{CS}_{0}$ (the maximal excitation trapping rate that will lead to $Q_{A}$ reduction measured over a cross-section of active and inactive RCs), TR/
ABS $\left(F_{v} / F_{m}\right.$ ratio, the probability that an absorbed photon will be trapped by the PS II RC with the resultant reduction of $Q_{A}$ ) $\mathrm{e}$ $\mathrm{Dl}_{0} / \mathrm{RC}$ (the ratio of the total dissipation of untrapped excitation energy from all RCs with respect to the number of active RCs) (Force et al., 2003).

Statistical analysis: For the biometric measurements, $A, g_{s}, V P D$, IWUE, $A_{\text {daily }}$ and chlorophyll contents a six casual block design with 3 replicates were used. For the chlorophyll fluorescence was used a five casual block design with nine replicates. For SLA, dry weight and their ratios the design was casualized with 8 replicated. The results were submitted to an ANOVA, followed by the Tukey's test for mean comparison, at $5 \%$ of probability using the SAEG system.

\section{RESULTS}

Sharp increase in the length of central vein (LCV) was observed in all studied genotypes between 42 and 56 DAS (Figure 2). After that differences in LCV became significant, with the Tainung genotype showing higher values than Hybrid, Solo 7212 and Golden.

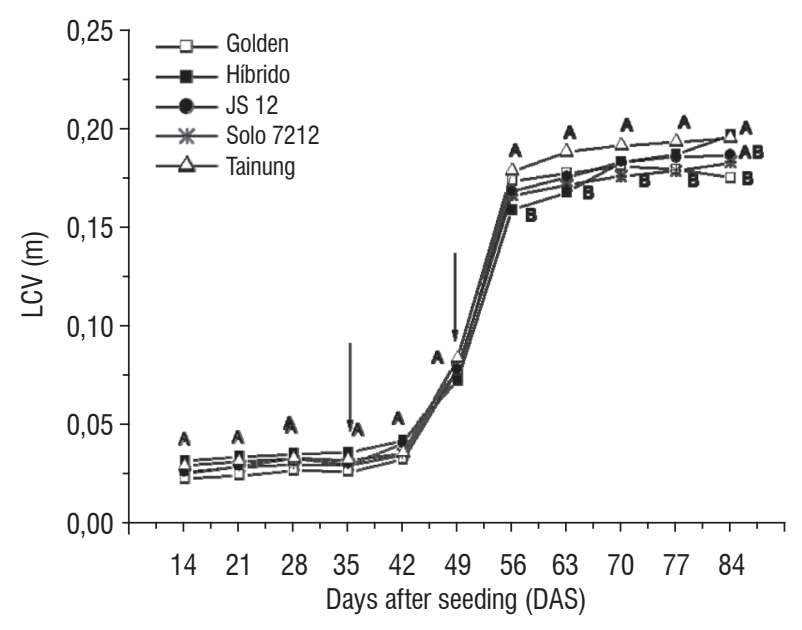

Figure 2. Length of central vein (LCV) increase of leaves from the 5 genotypes of Carica papaya $L$ in function of time. Each symbol represents the average of 18 replicates. Averages with the same letter did not show statistic differences (Tukey 5\%). The arrow shows the days when gas exchange measurements were carried out.

The Golden genotype showed the lowest plant height $(\mathrm{H})$ among 35 DAS ( $\left.17^{\text {th }}\right)$ and 49 DAS (30 th) October (Figure 3A) while Tainung presented the highest plant height from 35 DAS ( $17^{\text {th }}$ October) onwards. Furthermore, Golden showed also the lowest shrunk diameter values (D) (Figure 3B) starting at 42 
DAS (24 ${ }^{\text {th }}$ October) until the end of the experiment and Tainung was the highest. The other genotypes presented intermediate values for LCV, $\mathrm{H}$ and $\mathrm{D}$, with non-significant differences among them or with Golden and Tainung during the studied period.

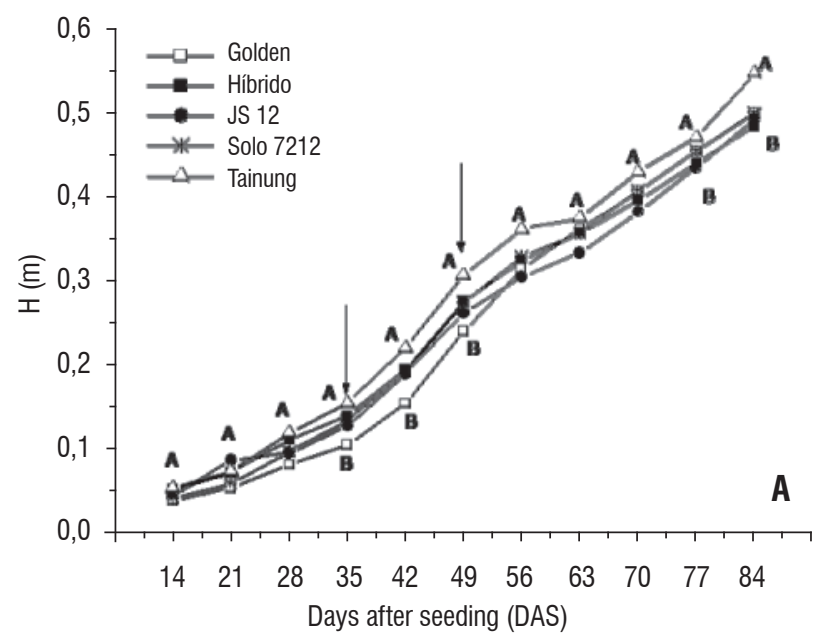

During the experiment the genotypes did not differ significantly in the number of leaves per plant, except on the last date (6 December), when Golden presented a higher value when compared to Solo 7212 (Figure 4).

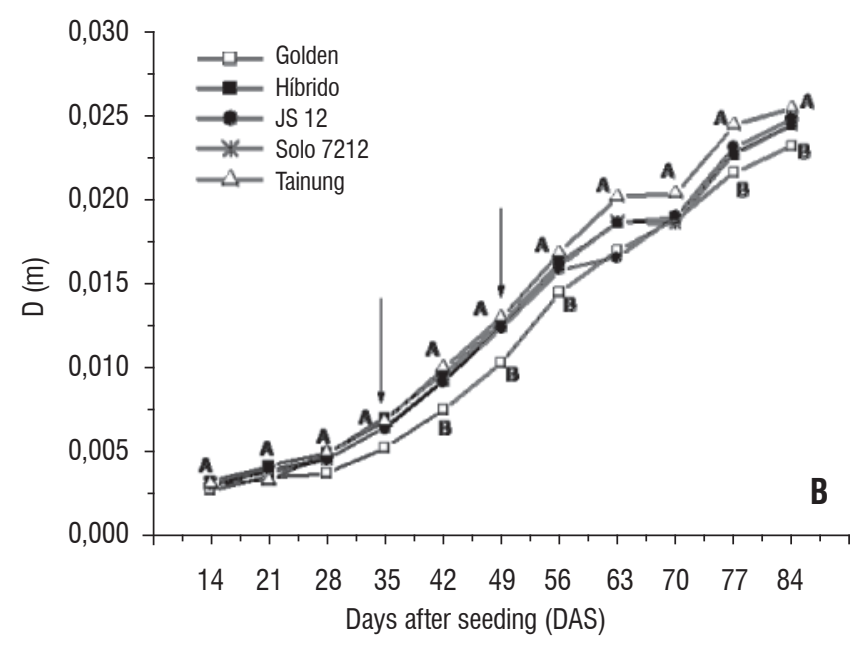

Figure 3. Height $(\mathrm{H})$ and shrunk diameter $(\mathrm{D})$ increase of leaves from Carica papaya L. plants in function of time. Each symbol represents the average of 18 replicates. Averages with the same letter did not show statistic differences (Tukey 5\%). The arrow shows the interval days when gas exchange measurements were carried out.

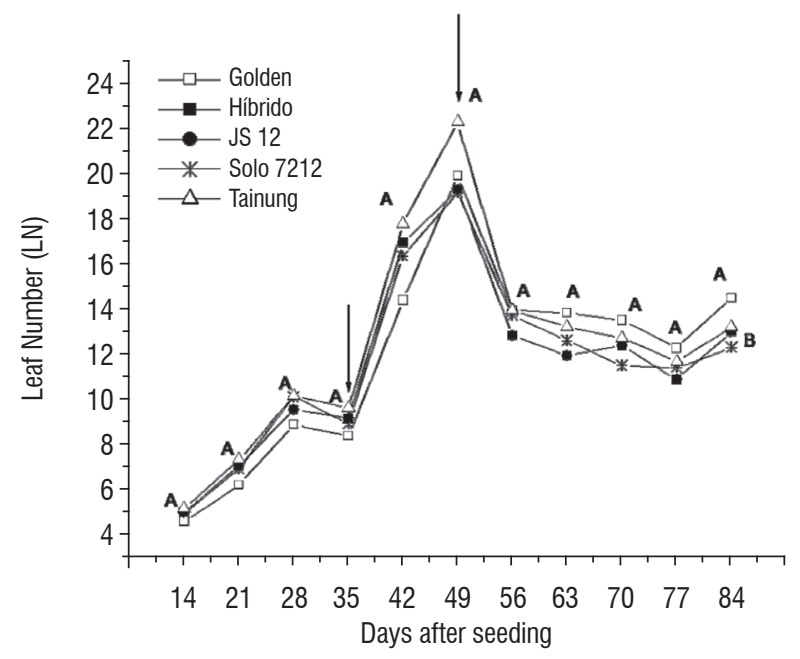

Figure 4. Leaf number increase in function of time (LN) of the 5 genotypes of Carica papaya L. Each symbol represents the average of 18 replicates. Averages with the same letter did not show statistic differences (Tukey 5\%). The arrows show the dates when gas exchange measurements were carried out.

Golden is a mutant of Solo genotype, known by its yellowish-green leaves, as reflected by the lowest values obtained with the portable chlorophyll device (SPAD-502) when compared to the other genotypes (Fig. 5). Based in previous work (Torres Netto et al., 2002, Castro, 2005), that obtained a positive correlation between PCM values and the total chlorophyll content, Golden presents the lowest amount of total chlorophyll. Furthermore, from 64 DAS onwards Golden is the only genotype that showed a decrease in the PCM values. During the experiment the other four genotypes did not present significant differences among them.

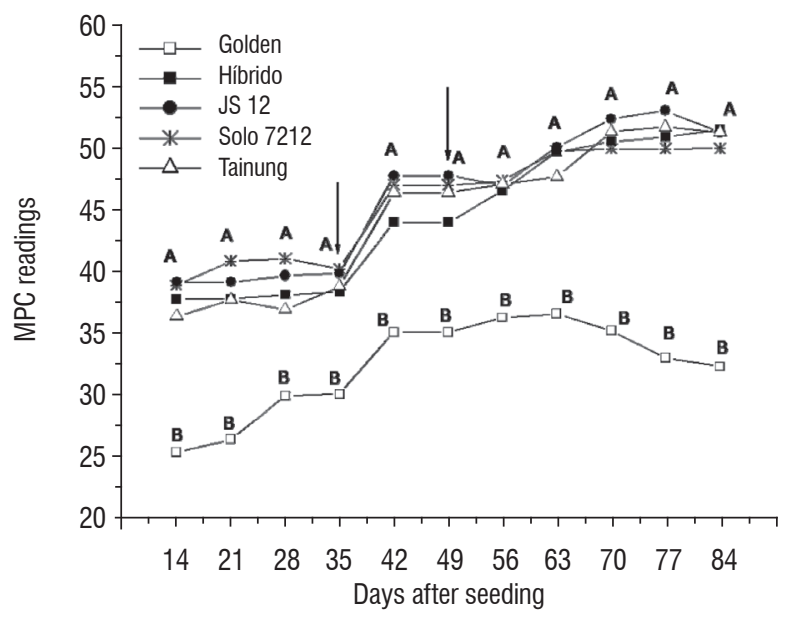

Figure 5. Measurements of the Portable Chlorophyll Meter (PCM) in leaves of the 5 genotypes of Carica papaya L. Each symbol represents the average of 18 replicates. Averages with the same letter did not show statistic differences. The arrows show the dates when gas exchange measurements were carried out. 
The thickness of the leaves was evaluated by the specific leaf weight (SLW, dry weight per leaf area), had a variation between $30.5 \mathrm{~g} \mathrm{~m}^{-2}$, observed in Golden and $37 \mathrm{~g} \mathrm{~m}^{-2}$ presented in Solo 7212 genotype (Figure 6). At the end of the experiment, the total leaf area per plant (LA) of each genotype did not show significant differences among the genotypes (Figure 7).

In what concerns biomass accumulation, Golden showed the lowest values for shoot (SDW) and root dry weight (RDW), and the higher shoot/root ratio (SDW/RDW) (Figure 8), reflecting a proportional lower investment in root biomass.

The leaf area ratio (LAR) is a morphological characteristic that represents the leaf area which is available to the

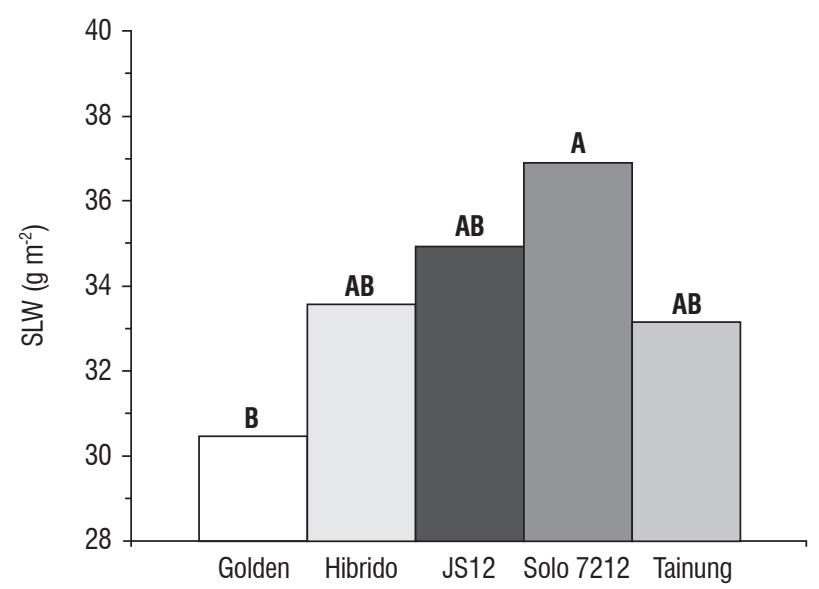

Figure 6. Specific leaf weight (SLW) of the 5 genotypes of Carica papaya L. Each column represents the average of 8 replicates. Averages with the same letter did show statistical differences. photosynthetic process (Cruz et al., 2004), while the leaf weight ratio (LWR) characterize the plant capacity to mobilize the produced assimilates to form new assimilator organs (leaves). The Golden genotype showed the highest LAR and LWR values (probably related to the higher $L N$ showed at the end of the experiment (Figure 4), while Tainung presented the lowest values for these parameters (Figure 8). Golden also showed the lowest stem weight ratio (SWR).

Concerning the leaf gas exchange data, the genotypes showed a higher photosynthetic rate (A) at $800 \mathrm{~h}$ than in afternoon (1200 h), except in Golden (Figure 9) that presented a similar value in both determinations. However, all genotypes showed a higher $g_{s}$ value at this time of the day $(800 \mathrm{~h})$, comparing to that measured at noon.

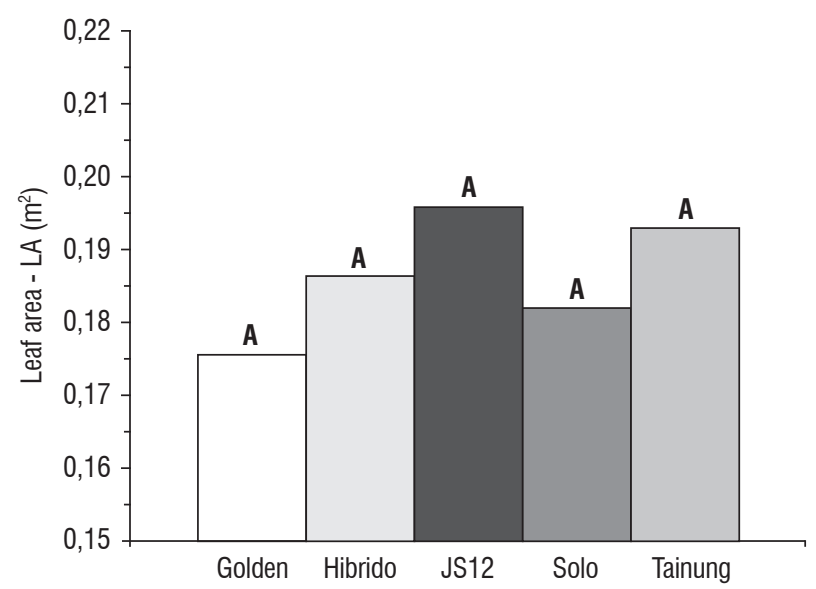

Figure 7. Leaf area per plant (LA) values of the 5 genotypes of Carica papaya L. Each symbol represents the average of 8 replicates. Averages with the same letter did not show statistic differences. 

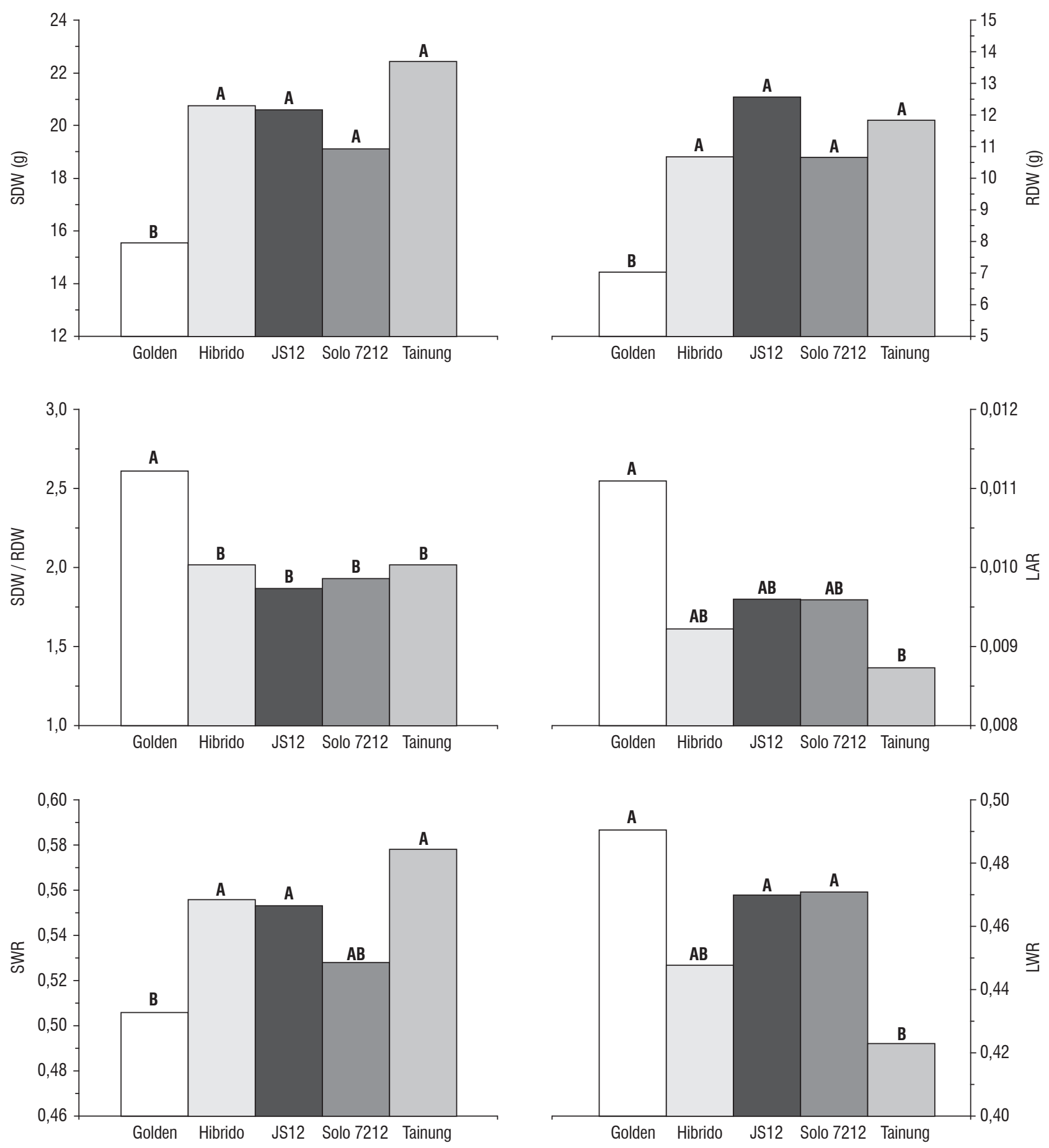

Figure 8. Shoot dry weight (SDW), Root dry weight (RDW), Leaf area ratio (LAR), Leaf weight ratio (LWR), Stem weight ratio (SWR) and Shoot / root dry weight ratio (SDW/RDW) of the 5 genotypes of Carica papaya L. with 92 days after seedling (DAS). Each column represents the average of 8 replicates. Averages with the same letter did not show statistical differences. 

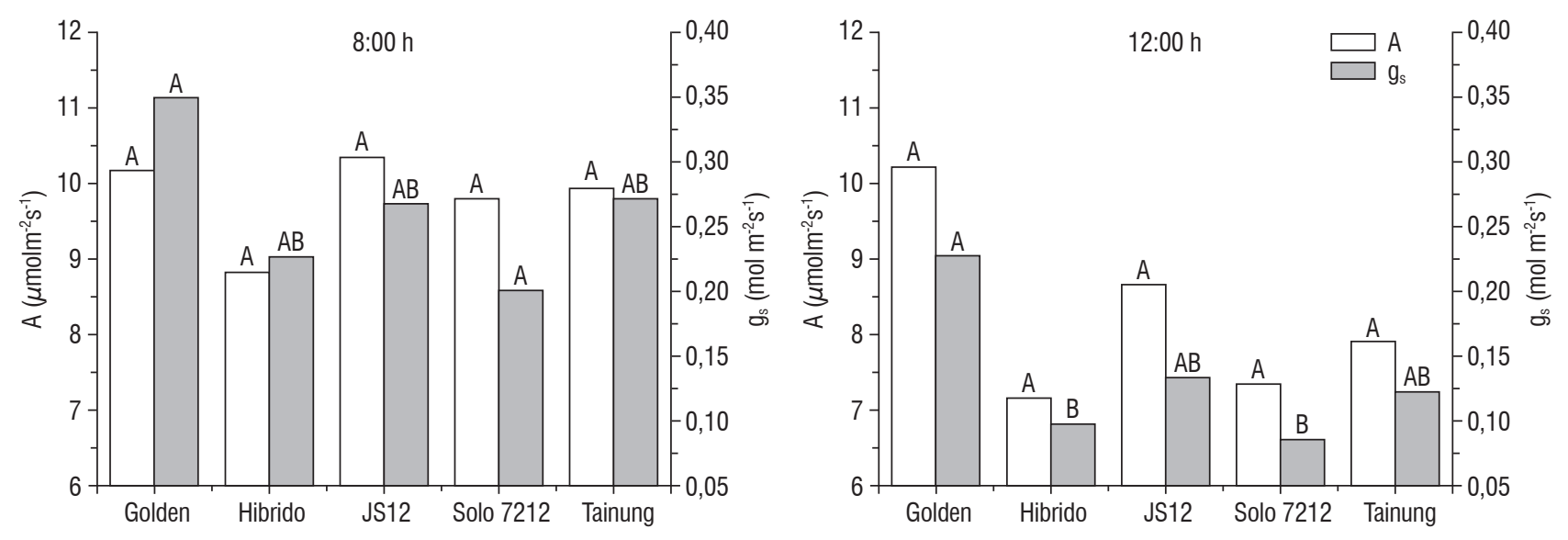

Figure 9. Photosynthetic rate $(A)$ and stomatal conductance $\left(g_{s}\right)$ in the leaves of the 5 genotypes of Carica papaya L. Each column represents the average of 18 replicates. Averages with the same letter did not show statistic differences.

The $A$ values did not statistically differ among the genotypes at $800 \mathrm{~h}$ or at $1200 \mathrm{~h}$. Significant differences were observed in $\mathrm{g}_{\mathrm{s}}$ at $800 \mathrm{~h}$, with Solo 7212 presenting the lowest value $\left(0.200 \mathrm{~mol} \mathrm{~m}^{-2} \mathrm{~s}^{-1}\right)$ and Golden the highest $(0.350 \mathrm{~mol}$ $\left.\mathrm{m}^{-2} \mathrm{~s}^{-1}\right)$. At midday, Golden showed the highest $\mathrm{g}_{\mathrm{s}}$ value $(0.24$ $\mathrm{mol} \mathrm{m} \mathrm{m}^{-2} \mathrm{~s}^{-1}$ ), representing between 65\% (JS12) and 190\% (Solo 7212) more than what was observed in the other genotypes. This fact showed a higher sensitivity of these genotypes to the air dryness, as accessed by the rise in the leaf-to-air vapor pressure deficit $\left(\mathrm{VPD}_{\text {leaf-air }}\right.$ ) at noon (Fig. 10).
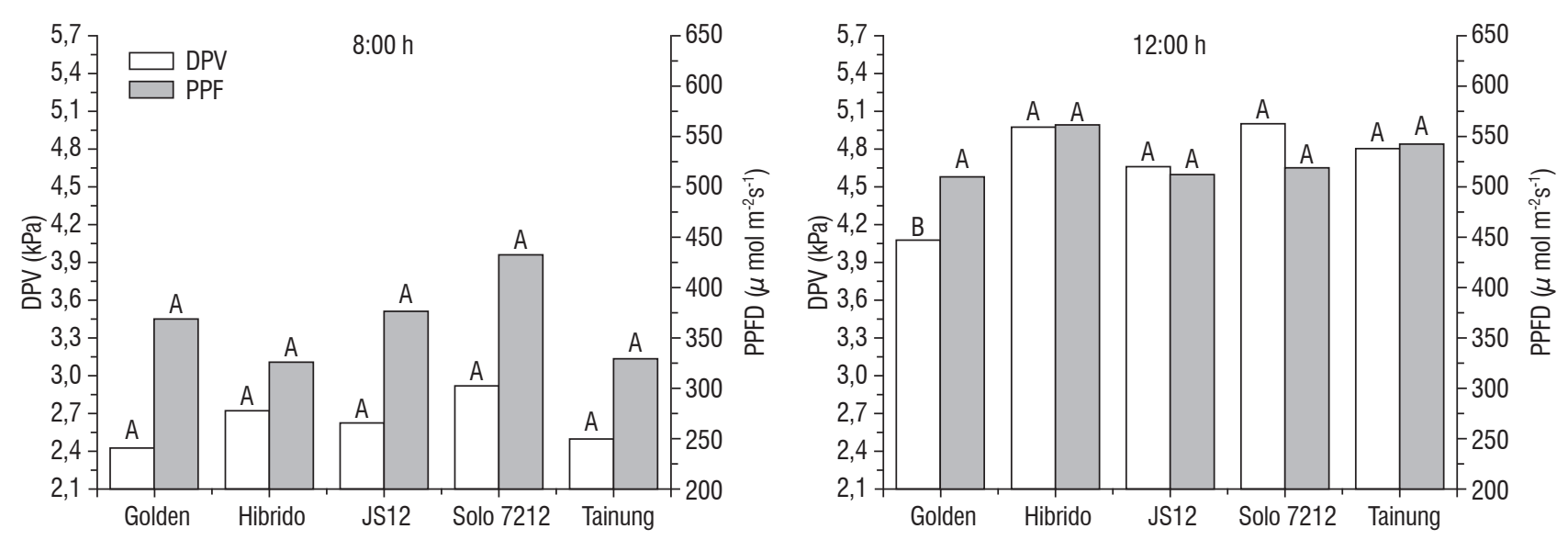

Figure 10. Leaf-to-air vapor pressure difference (VPD $\mathrm{Veaf-air}_{\text {) }}$ and photosynthetic photon flux density (PPFD) in the growing site of the 5 genotypes of Carica papaya L.. Each column represents the average of 18 replicates. Averages with the same letter did show statistic differences. 
In both times of the day, Golden displayed the lowest intrinsic water use efficiency (IWUE) values (Fig. 11), reflecting its higher $g_{s}$ values, once the statistical differences for the $A$ values are not significant (Fig. 9).

The daily carbon gain $\left(\mathrm{A}_{\text {daily }}\right)$ reached maximal values in Golden and Tainung (Fig. 12). In the Golden genotype this can be explained by the highest A values in the hottest time of the day $(1200 \mathrm{~h})$. The Tainung genotype presented the higher A rate at $1000 \mathrm{~h}$, that contribute for the highest carbon gain values comparing with the JS12 genotypes (data not shown). This characteristic can be interesting to be used in papaya improvement programs.

The total number of photons absorbed by the antenna molecules of active and inactive PS II RCs over the sample cross-section $\left(A B S / C S_{0}\right)$ did not show significant differences among the studied genotypes for each time of the day time (Fig. 13A). So despite the lower total chlorophyll content in Golden (Fig. 5), the PPFD absorption per cross section in

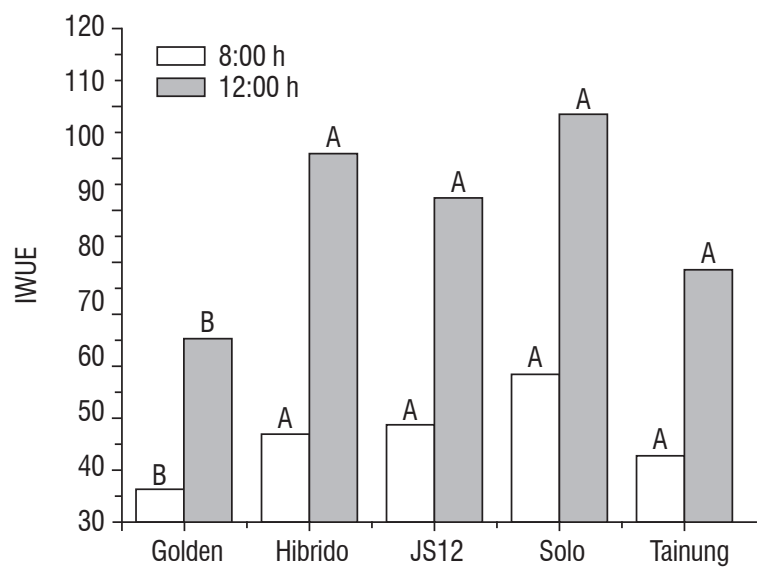

Figure 11. Intrinsic water use efficiency (IWUE) for the 5 genotypes of Carica papaya L. Each column represents the average of 18 replicates. Averages with the same letter did not show statistic differences. those samples was not affected. The high value of $\mathrm{ABS} / \mathrm{CS}_{0}$ at midday reflects the higher values of PPFD (Fig. 10). The same pattern occurred in $\mathrm{Dl}_{0} / \mathrm{RC}$, the ratio of the total dissipation of untrapped excitation energy from all RCs with respect to the number of active RCs (Force et al., 2003) (Fig. 13B). The high energy dissipation in Golden at midday could be responsible by the lower use of energy to electrons transport $\left(\mathrm{ET}_{0} / \mathrm{CS}_{0}\right)$ and a lower $Q_{A}$ reduction $\left(\mathrm{TR}_{0} / \mathrm{CS}_{0}\right.$ ) (Fig. 13C, F), but allowing the highest $A$ value at noon (Fig. 9).

The probability that an absorbed photon will be trapped by the PS II RC with the resultant reduction of $Q_{A}$ (TR/ABS, the same as $F_{v} / F_{m}$ ) shows that instead of the Golden genotype present the lowest values to this parameter, comparing among the genotypes, this parameters was keep above 0,75. At $800 \mathrm{~h}$ Golden showed the highest concentration of active reaction centres ( $\left.\mathrm{RC} / \mathrm{CS}_{0}\right)$ (Fig. 13D), while, at midday this parameter did not show significant differences among genotypes.

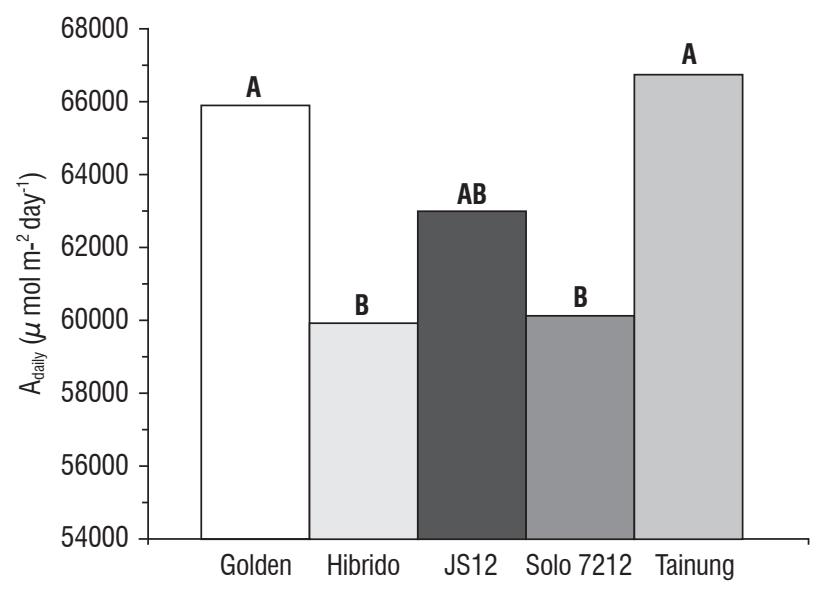

Figure 12. Daily carbon gain $\left(A_{\text {daliy }}\right)$ for the 5 genotypes of Carica papaya $L$. Each column represents the average of 18 replicates. Averages with the same letter did not show statistic differences. 

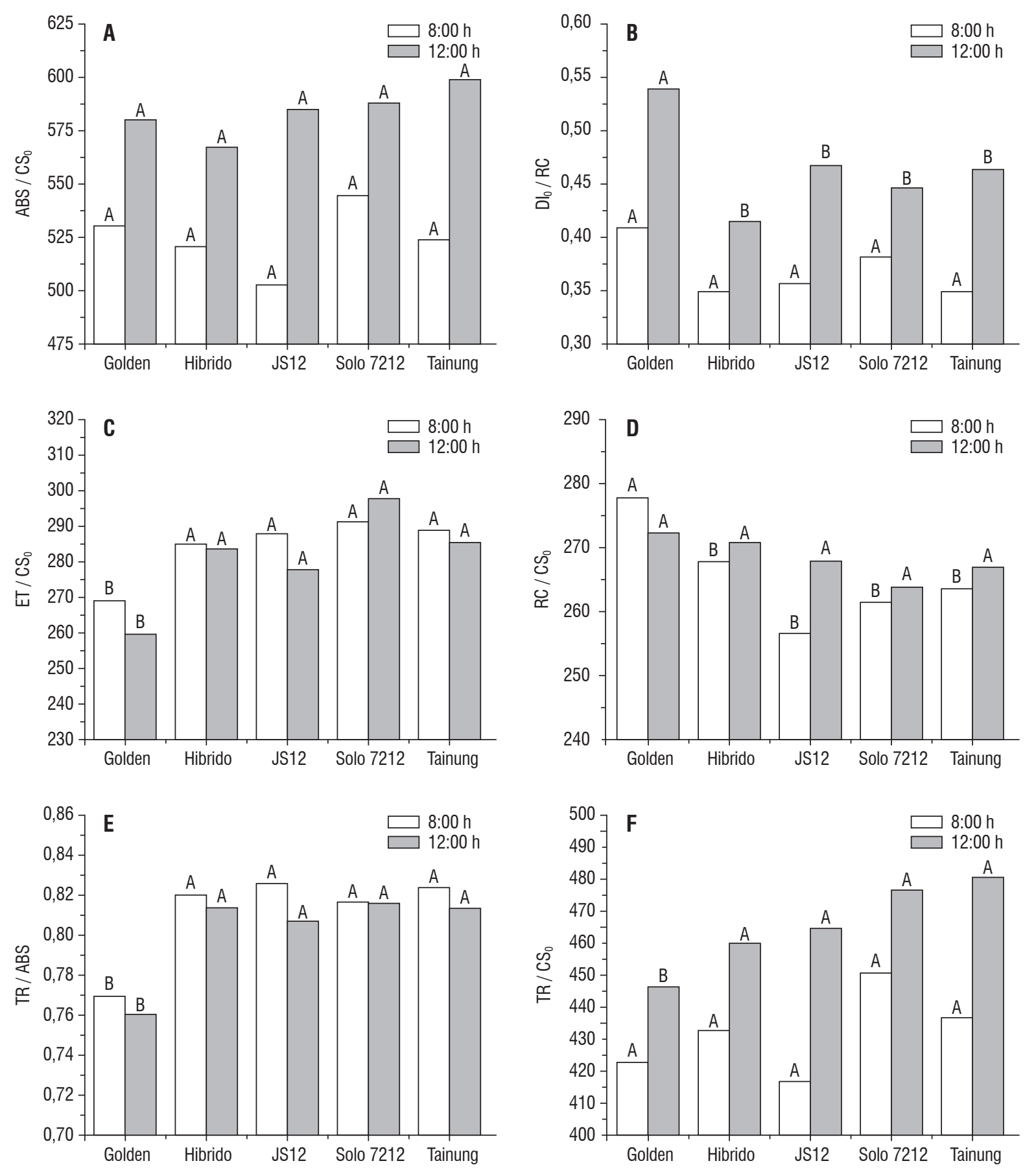

Figure 13. Chlorophyll fluorescence data: A) ABS/CS , B) Rl/RC, C) ET/CS, D) RC/CS, E) TR/ABS and F) TR/CS ratios for the 5 genotypes of Carica papaya $\mathrm{L}$. Each column represents the average of 18 replicates. Averages with the same letter did not show statistic differences, in each time. 


\section{DISCUSSION}

Analysis of the canopy structure and photosynthetic performance under environmental limiting conditions are essential to evaluate plant-environment interactions, acclimation ability and the impact on crop productive capacity (Magalhães, 1979, Villar et al., 2005). Biometric studies along the plant life cycle can be a helpful tool to evaluate the genotype productive capacity. The lower performance of the Golden in growth analysis (Fig. 2 to 5) help to explain why this genotype had lower productivity (datanotshown) as compared to the othergenotypes but clearly other physiological traits should contribute to this problem. SLW represents leaf thickness and gives an estimative of the proportion between the assimilatory surface and the veins that sustain those leaf tissues (Evans, 1972, Cruz et al., 2004). Plants with a higher SLW are usually greener (Barnes et al., 1969) because they have more cell layers and chloroplasts/ chlorophyll, what could represent a higher photosynthetic potential. Golden leaves are thinner (Fig. 6), what agrees with its lowest PCM values (Fig. 5), but the A (Fig. 10) and $A_{\text {daily }}$ (Fig. 12) were among the higher values observed for the studied genotypes. SLW have been correlated with the photosynthetic rate (Pearce et al., 1969), growth relative rate (Poorter and Van der Werf, 1998), production (Pearce et al., 1969, and leaf structure (Cambridge and Lambers, 1998). It fact, in our study because the lower SLW values of the Golden genotype could be related to the lower values in growth parameters and chlorophyll content, as well as with the lower productivity (data not shown), but not with the net photosynthetic rates.

The lower PCM values in Golden after 63 DAS (Fig. 5) could point out for lower leaf longevity, and an earlier senescence process (Thomas and Howarth, 2000) as compared to the other genotypes that continuously increased chlorophyll content up to the end of the experiment. Such earlier senescence process could also be related to the lower productivity of this genotype.

The Golden yellowish-green leaves color could have contributed to raise the leaf reflectance (Bauerle et al., 2004). Furthermore $g_{s}$ were maintained at higher values even by the middle of the day (Fig. 10). Stomata have the role to control the leaf temperature (Larcher, 2000) and transpiration may reduce the difference among leaf and air temperature up to $8^{\circ} \mathrm{C}$ (Wilkinson, 2004). Consequently, the leaf temperature of genotype did not increase so much (data not shown), what might have contributed to a lower VPD leaf-air value (Fig.
10) and higher A rates in this genotype at midday. In fact, in other papaya plants high $\mathrm{VPD}_{\text {leaf-air }}$ causes $\mathrm{g}_{\mathrm{s}}$ decreases and, consequently, in A (El-Sharkawy et al., 1986, Reis et al, 2006, Campostrini and Glenn, 2007).

Midday depression of the photosynthesis is a common occurrence in many plants, such as grapevines (Correia et al., 1995), lupine (Correia and Pereira, 1994), corn (Tardieu et al., 1992) and sunflower (Tardieu et al., 1996). Such $g_{s}$ decrease due to high $\mathrm{VPD}_{\text {leat-air }}$ would help to postpone cell drought stress, imposed by environment conditions (Maroco et al., 1997, Franks and Farquhar, 1999), but by reducing $\mathrm{CO}_{2}$ internal partial pressure $\left(\mathrm{pC}_{\mathrm{i}}\right)$ would limit $\mathrm{CO}_{2}$ access to Rubisco carboxylation sites (Maroco et al., 1997). On the other hand, well watered plants without $g_{s}$ midday depression could maintain photosynthetic rates, configuring a potential production advantage. Such lower stomatal sensitivity to VPD could result from on a higher leaf hydraulic conductance (Schulze, 1994), compensating the higher water losses and preventing transient drought stress.

Those differences among genotypes related to stomatal responses to $\mathrm{VPD}_{\text {leaf-air }}$ can be useful to agriculture management and genetic improvement programs for the species. Taken together these data with the yellow-green color trait of Golden leaves and the maintenance of $A$ rates can be used to genetic improvement programs directed to produce genotypes with lower leaf temperatures and high $g_{s}$ and $A$ rates in the hottest time from the day. A similar strategy proved to be of great importance for improvement programs of cotton and wheat (Lu et al., 1994).

The control of stomatal closure, together with A, determines the water use efficiency (WUE) (Nobel, 1991), that is, the balance between the carbon assimilated and water consumed. An efficient stomatal control is an important adaptation trait, allowing the plants to keep the water potential under water deficits, even the temporary ones (Chaves, 1991, Schaffer and Andersen, 1994). For Golden, the high A values observed at 1200 and the high $g_{s}$ values led to this genotype to consuming more water per assimilated $\mathrm{CO}_{2}$ unit a lower IWUE (Fig. 11), while in the other genotypes no differences were found. Lower IWUE as a result of high values of $g_{s}$ was found by Franks and Farquhar (1999) and Larcher (2000) in herbaceous plants too. 
Despite the high $g_{s}$ at midday, responsible by the high daily carbon gain (Fig. 12), the Golden genotype is not the most productive among the top commercial genotypes in number and weight of fruits (Caliman Agrícola SA Company, personal communication). In fact, the final productivity of plants is a complex process and according to Nelson (1988), the absence of a positive correlation among the photosynthetic rate and productivity could explained by other factors like number/size and duration of leaves, as well as the partitioning of photoassimilates among the source and sink organs.

Chlorophyll a fluorescence is emitted by the photosystem (PS) II and by the light harvest complex of PSII (LHCII). So, changes in its emission patterns suggest the existence of impairments in the photosynthetic process (Strasser et al., 2000). The kinetic quantitative analysis of chlorophyll a fluorescence was proposed by Strasser and Strasser (1995), based on the biomembranes theory for energy flux. This energy flux integrates processes occurring in the antenna pigments of PSII (ABS), flux to reduced $Q_{A}$ (TR), the energy used to electron transport (ET) and by the energy dissipation (e.g., as heat, fluorescence or transmission to another systems) (DI) (Strasser et al., 2000). This analysis was called JIP-Test and can be use to obtain information about each step of energy flux through PS II at the reaction center level (RC) (ABS/RC, $\mathrm{TR}_{0} / \mathrm{RC}, \mathrm{ET}_{0} / \mathrm{RC}$ and $\mathrm{DI}_{0} / \mathrm{RC}$ ), as well as the level of energy at PS II by cross-section (CS) (ABS/CS, $\mathrm{TR}_{0} / \mathrm{CS}_{0}, \mathrm{ET}_{0} / \mathrm{CS}_{0}$ and $\left.\mathrm{DI}_{0} / \mathrm{CS}_{0}\right)$. The parameters are inter-related by probabilities that define excitation trapping (TR/ABS) and electron transport $\left(\mathrm{ET}_{0} / \mathrm{TR}_{0}\right.$ ) (Force et al., 2003). In this way, the JIP-Test is used to give an idea of a vitality of the plant material analyzed (Strasser et al., 2000), simplifying the fluxes energy theory, but still considering the antenna complex structure (pigment arrangement, excitation migration and connectivity) (Force et al., 2003).

Based on the JIP-Test the Golden genotype showed that, following the low values of chlorophyll (Fig. 5) and SLW (Fig. 6), the PSIl efficiency was significantly affected, but maintained its efficiency higher than 0.75, as given by TR/ABS (Fig. 13E). According to Bolhàr-Nordenkampt et al. (1989), the $F_{v} / F_{m}$ values between 0.75 and 0.85 , means that an each hundred photons arrive in PSII, 75 to 85 are use to reduce $Q_{A}$, leading to a high PSII efficiency. This would have contributed to the similar (or higher, at 1200) photosynthetic rates observed in Golden when compared to the other genotypes. The other fluorescence parameters confirm this results, showing that Golden maintains most of the parameters concerning the electron transport ratio to reduce $\mathrm{Q}_{\mathrm{A}}\left(\mathrm{ABS} / \mathrm{CS}_{0}, \mathrm{RC} / \mathrm{CS}_{0}, \mathrm{TR} /\right.$ $\mathrm{CS}_{0}$ ) and present higher dissipation of excess energy ( $\mathrm{Dl}_{0} /$ $\mathrm{RC})$, specially at midday.

Golden had the lowest SDW and RDW values, but the higher SDW/RDW (Fig.8), reflecting a higher investment in shoot biomass, specially in leaves (confirmed by the higher values of LAR, LWR and a lower SWR). This might compensate for the lower SLW and PCM values to keep the photosynthetic rate even at higher values (at noon) than the other genotypes. In fact, it was the only genotype that present no midday A depression (higher $g_{s}$ at this time). Such higher $g_{s}$ values would have contributed to a better control of leaf temperature, thus helping to maintain of $A$. However that led to a lower IWUE. This property is of up most importance once high temperature and high light are common in the mains areas of papaya production in Brazil. Therefore, further papaya improvement programs should be planed to incorporate some qualitative traits from Golden in conjunction with the yield performance of the most productive genotypes.

\section{REFERENCES}

Anilkumar TV, Salimath PM, Parameshwarappa R, Chetti MB, Patil SS, Alagawadi AR, Patil SJ (1993). Genetic diversity on the basis of photosynthetic and yield related traits in chickpea (Cicer arietinum L.). Indian J. of genetic 53: $279-286$

Barnes DK, Pearce RB, Carlson GE, Hart RH, Hanson CH (1969) Specific leaf weight differences in alfalfa associated with variety and plant age. Crop Science 9: 421-423.

Bauerle WL, Weston DJ, Bowdena JD, Dudley JB and Toler JE (2004) Leaf absorptance of photosynthetically active radiation in relation to chlorophyll meter estimates among woody plant species. Scientia Horticulturae 101: 169-178.

Bolhàr-Nordenkampf HR, Long SP, Baker NR, Öquist G, Schreibers U, Lechner EG (1989) Chlorophyll fluorescence as a probe of the photosynthetic competence of leaves in the field: a review of current instrumentation. Functional Ecology 3: 497-514.

Cambridge ML, Lambers H (1998) Specific leaf area and functional leaf anatomy in Western Australian seagrasses. In: Inherent Variation in Plant Growth, Physiological Mechanisms and Ecological Consequences. $\mathrm{H}$. Lambers, H. Poorter \& M.M.I. Van Vuuren (eds). pp. 88-99, Backhuys Publishers, Leiden, The Netherlands.

Campostrini E, Glenn DM (2007) Ecophysiology of papaya: a review. Braz. J. Plant Physiol. 19(4): 413-424.

Castro F.A. (2005) Relações do valor do medidor portátil de clorofila (SPAD502) com o processo fotossintético e com o teor de nitrogênio orgânico em genótipos de Carica papaya L. Campos - RJ, Universidade Estadual do Norte Fluminense, Thesis.

Chaves M (1991) Effects of water deficits on carbon assimilation. J of Exp Bot 42 (234): 1-16. 
Chaves MM, Maroco J, Pereira JS (2003) Understanding plant responses to drought - from genes to the whole plant. Func. plant Biol 30: 239-264.

Cock JH, Porto MCM, El-Sharkawy MA (1985) Water use efficiency of cassava. III. Influence of air humidity and water stress on gas exchange of field grown cassava. Crop Sci 25: 265-272, 1985.

Correia MJ, Pereira JS, Chaves MM, Rodrigues ML, Pacheco CA (1995) ABA xylem concentrations determine maximum daily leaf conductance of fieldgrown Vitis vinifera L. plants. Plant Cell and Environment 18, 511-21.

Correia MJ, Pereira JS (1994) Abscisic acid in apoplastic sap can account for the restriction in leaf conductance of white lupins during moderate soil drying and after rewatering. Plant and Cell Environment 17: 845-852.

Cruz JL, Coelho EF, Pelacani CR, Coelho filho MA, Dias AT, Santos MT (2004) Crescimento e partição de matéria seca e de carbono no mamoeiro em resposta à nutrição nitrogenada. Bragantia 63(3):351-361.

Dornhoff GM, Shibles RM (1970) Varietal differences in net photosynthesis of soybean leaves. Crop Science 10: 42-45.

EI-Sharkawy MA (2004) Cassava biology and physiology. Plant Molecular Biol 56: 481-501, 2004.

El-Sharkawy MA (2006) International research on cassava photosynthesis, productivity, eco-physiology, and responses to environmental stresses in the tropics. Photosynthetica 44 (4): 481-512.

El-Sharkawy MA, Cock MJH, Hernandez ADP (1986) Stomatal response to air humidity and its relation to stomatal density in a wide range of warm climate species. Photosynthesis research 7: 137-149.

Evans GC (1972). The quantitative analysis of Plant Growth. Oxford: Blackwell Scientific publications.

Force L, Critchley C, Van Rensen JJS (2003) New fluorescence parameters for monitoring photosynthesis in plants. 1. The effect of illumination on the fluorescence parameters of the JIP-test. Photosynthesis Research 78: 17-33.

Franks PJ, Farquhar GD (1999) A relationship between humidity response, growth form and photosynthetic operating in $\mathrm{C}_{3}$ plants. Plant Cell and Environment 22: 1337-1349.

González A, Lynch J, Tohme JM, Beebe SE, Macchiavelli RE (1995) Characters related to leaf photosynthesis in wild populations and landraces in common bean. Crop Science 35: 1468-1476.

Hancock JF, Flore JA, Galletta GJ (1989) Gas exchange properties of strawberry species and their hibrids. Scientia Horticulturae 40: 139-144.

Heichel GH, Musgrave RB (1969) Varietal differences in net photosynthesis of Zea mays L. Crop Science 9: 483-486.

Joshi AK (1997) Genetic factors affecting photosynthesis. In: Handbook of photosynthesis. Pessarakli, M. (ed.). p. 751-767, Marcel Dekker, Inc.

Koehn AC, Roberds JH, Doudrick RL (2003) Variation among slash pine families in chlorophyll fluorescence traits. Can. J. For. Res. 33: 1102-1109

Larcher W (2000) Ecofisiologia Vegetal. Ed. RiMa Artes e Textos.

Lawlor DW (1995) Photosynthesis, productivity and environment. J of Exp Bot 46: 1449-1461.

Lu Z, Radin JW, Turcotte El, Perey R, Zeiger E (1994). High yields in advanced lines of Pima cotton are associated with higher stomatal conductance, reduced leaf area and lower leaf temperature. Physiologia Plantarum 92: 266-272.

Magalhães ACN (1979) Análise quantitativa do crescimento. FERRI, M.G. (Coord.). Fisiologia Vegetal. São Paulo: EPU.

Mahon JD, Hobbs LA (1981) Selection of peas for photosynthetic $\mathrm{CO}_{2}$ exchange rate under field conditions. Crop Science 21: 616-621.

Marler T, George AP, Nisser RJ, Perey R, Zeiger E (1994) Miscellaneous tropical fruits. In: Handbook of environmental physiology of fruit crops. CRC Press, Boca Raton.

Maroco JP, Pereira JS, Chaves MM (1997) Stomatal responses to leaf-toair vapour pressure deficit in sahelian species. Aust. J of Plant Physiol 24: 381-387.
Marshall JD, Rehfeldt GE, Monserud RA (2001) Family differences in height growth and photosynthetic traits in three conifers. Tree Physiol. 21: 727-734.

Nelson CJ (1988) Genetic associations between photosynthetic characteristics, yield: Review of the evidence. Plant Physiology and Biochemistry 26 (4): 543-554.

Nobel PS (1991) Physicochemical and Environmental Plant Physiology. Academic Press, New York.

Pearce RB, Carlson GE, Barnes DK, Hart RH, Hanson CH (1969) Specific leaf weight and photosynthesis in alfalfa. Crop Science 9: 423-426.

Peet MM, Kramer PJ (1980) Effects of decreasing source/sink ratio in soybeans on photosynthesis, photorespiration, transpiration and yield. Plant, Cell \& Environment 3(3): 201 - 206

Peng S, Krieg DR, Girma FS (1991) Leaf photosynthetic rate is correlated with biomass and grain production in grain sorghum lines. Photosynthesis Research 28: 1-7

Perry SW, Krieg DR, Hutmacher RB (1983). Photosynthetic rate control in cotton. I. Photorespiration. Plant Physiology 73: 662-665.

Pettigrew WT (2004) Cotton genotypic variation in the photosynthetic response to irradiance. Photosynthetica 42 (4): 567-571

Pettigrew WT, Hesketh JD, Peters DB and Wooley JT (1990). A vapor pressure deficit effect on crop canopy photosynthesis. Photosynthesis Research 24: 27-34.

Pettigrew WT, Gerik TJ (2007) Cotton leaf photosynthesis and carbon metabolism_In: Advances in Agronomy, pp.209-230.

Pettigrew WT, Turley RB (1998) Variation in photosynthetic components among photosynthetically diverse cotton genotypes. Photosynthesis Research 56: 15-25.

Poorter H, Van der Werf A (1998) Is inherent variation in RGR determined by LAR at low irradiance and by NAR at high irradiance? A review of herbaceous species. In: Inherent variation in plant growth Physiological mechanisms and Ecological Consequences. Lambers H Poorter H van Vuuren M (eds). pp 309-336, Backhuys Leiden.

Reis FO, Campostrini E, Sousa EF, Silva MG (2006) Sap flow in papaya plants: Laboratory calibrations and relationships with gas exchanges under field conditions. Scientia Horticulturae 110: 254-259

Schaffer B, Andersen PC (1994) Handbook of environmental physiology of fruit crops. CRC Press Boca Raton.

Schulze ED (1994) The regulation of plant transpiration: interactions of feedforward feedback and futile cycles. In: Flux control in biological systems: From enzymes to populations and Ecosystems (Ed. Schulze ED), pp.203235, Academic Press.

Singels A, Donaldson RA, Smit MA (2005) Improving biomass production and partitioning in sugarcane: theory and practice. Field Crops Research 92: 291-303.

Strasser BJ, Strasser RJ (1995) Measuring fast fluorescence transients to address environmental questions: the JIP- Test. In: Photosynthesis: from light to biosphere. Mathis P (ed). p.977 - 980. The Netherlands: Kluwer academic publishers.

Strasser RJ, Srivastava A, Tsimilli- Michael M (2000) The fluorescence transient as a tool to characterise and screen Photosynthetic Samples. In: Probing photosynthesis: mechanisms regulation and adaptation. Yunus M, Pathre U, Mohanty P, Taylor \& Francis (Eds) pp.445-483. London.

Tardieu F, Lafarge T, Simonneau T (1996) Stomatal control by fed or endogenous xylem $A B A$ in sunflower: interpretation of observed correlations between leaf water potential and stomatal conductance in anisohydric species. Plant Cell and Environment 19: 75-84.

Tardieu F, Zhang J, Davies WJ (1992) What information is conveyed by an ABA signal from maize roots in drying field soil? Plant Cell and Environment 15 185-91 
Thomas H, Howard C (2000) Five ways to stay green. Journal of experimental botany 51: 329-337.

Torres Netto A, Campostrini E, Oliveira JG, et al (2002) Portable chlorophyll meter for the quantification of photosynthetic pigments nitrogen and the possible use for assessment of the photochemical process in Carica papaya. Brazilian Journal of Plant Physiology 14(3): 203-210.

Villar R, Maranon T, Quero JL, Panadero P, Arenas F, Lambers H (2005) Variation in relative growth rate of 20 Aegilops species (Poaceae) in the field: The importance of net assimilation rate or specific leaf area depends on the time scale. Plant and Soil 272: 11-27.
Watanabe N, Kobayashi S, Furuta Y (1997) Effect of genome and ploidy on photosynthesis of wheat. Euphytica 73: 191-198.

Wiebold WJ, Shibbles R, Green DE (1981) Selection of apparent photosynthesis and related leaf traits in early generations of soybeans. Crop Science 21: 969-973.

Wilkson S (2004) Water use efficiency and chemical signaling. In: Water use efficiency in plant biology. Bacon M.A. Blackwell Publishing Ltda.

Zelitch I (1982) The close relationship between net photosynthesis and crop yield. BioScience 32: 796-802. 